\title{
Documentação e Segurança Nacional
}

\author{
Edson Nery da Fonseca
}

\author{
Diretor da Faculdade de \\ Estudos Sociais Aplicados (UnB)
}

\begin{abstract}
RESUMO
Implicações documentológicas do moderno conceito de segurança nacional, que envolve todos os recursos da nação e não apenas a tecnologia militar. Conseqüências bibliográficas da explosão científica e tecnológica, bem como da íntima ligação entre ciência e tecnologia. A biblioteconomia e o advento das modernas técnicas documentológicas. Semelhança do conflito entre biblioteconomia e documentação com a disputa entre historiadores e sociólogos. A dispersão de informações de interesse para a segurança nacional em revistas de múltiplas especializações indica o caráter interdisciplinar de um serviço de documentação destinado às forças armadas. A aquisição de equipamento eletrônico deve ser precedida por um inquérito que defina os perfis de interesse dos usuários, objetivando o provimento de informações personalizadas. O importante papel do EMFA como órgão coordenador dos serviços de documentação das três Armas.
\end{abstract}

\section{1 - MODERNO CONCEITO dE SEGURANÇA NACIONAL}

Em versos famosos do seu poema épico, disse Camões que "a disciplina militar prestante / Não se aprende, Senhor, na fantasia, / Sonhando, imaginando ou estudando, / Senão vencio, tratando e pelejando". ${ }^{1}$ Quando o grande poeta escreveu isto, em meados do século XVI, era admissível que a carreira militar consistisse apenas em ver, tratar e pelejar. Essa concepção durou até o início do século atual, quando um estadista como Clemen- 
ceau podia dizer que "a guerra é assunto sério demais para ser entregue a militares".

Os próprios generais da nossa época sabem muito bem que as guerras não se decidem apenas nos campos de batalha. As implicações econômico-financeiras das operações militares podem ser exemplificadas, no Brasil, por conhecida boutade: a de que a Revolução de 1930 foi feita pelo "general café", pois o crack da Bolsa de Nova York, em outubro de 1929, deixou em pânico os cafeicultores brasileiros, provocando a queda do Governo Washington Luis.

Sonhar, imaginar e estudar são hoje, conseqüentemente, tâo importantes para os militares quanto o ver, tratar e pelejar. O papel do sonho e da imaginação da gênese das grandes descobertas é reconhecido pelos estudiosos da criação científica e atestado por depoimentos de grandes inventores e pesquisadores. professor Maurício Rocha e Silva tem observações muito lúcidas sobre o assunto, em seu notável livro A Evolução do Pensamento Científico. ${ }^{2} \mathrm{O}$ estudo, por sua vez, é indispensável à pesquisa, pois como observa Bright Wilson, "seis horas na biblioteca podem poupar seis meses no laboratório". ${ }^{3}$

Em seu livro Neither war nor peace, Hugh Seton-Watson define os militares da nossa época - uma época ao mesmo tempo e complexamente de paz e de guerra - como "intelectuais em uniforme". "E Gilberto Freyre, em recentíssimo artigo nesta revis. ta, comentando as idéias de Seton-Watson, escreve: "Seriam intelectuais no sentido, não de serem literatos ou beletristas, acadêmicos ou eruditos só de gabinete, mas expressões daquela inteligência analítica, daquela imaginação científica, daqueles saberes mais concretos do que abstratos, que precisam, atualmente mais do que nunca, de estarem a serviço da direção das forças militares de uma nação ou de um conjunto de nações nas áreas em que essa direção deixa de corresponder ao controle de simples - se é que podem ser considerados simples - recursos tecnológicos de segurança nacional ou supranacional pelas armas para se relacionarem com aspectos outros - econômicos, sociais, culturais e não apenas políticos e diplomáticos - daquele tipo novo de segurança. Palavra essa - segurança - que tem um sentido atualíssimo e, repita-se em grande parte, extramilitar, a dinamizá-la de tal maneira que é como se fosse uma palavra nas. cida de novo nos nossos dias. Não se trata de arcaica segurança, estática e simplesmente militar, mas de outra : dinâmica e complexa".5 
O que estou querendo demonstrar com este preâmbulo ? A legitimidade do moderno conceito de segurança nacional, que envolve todos os recursos da nação e não apenas, como antigamente se pensava, o material bélico. Um dos paradoxos da nossa época é o de haver provocado especializações à outrance, demonstrando, ao mesmo tempo, que nenhuma delas é suficiente para resolver qualquer problema. Pois nenhum problema existe sem imediata ou remota correlação com outros, donde a necessidade dos estudos interdisciplinares.

A frase de Clemenceau deveria ser substituída por esta : qualquer assunto ou problema é complexo demais para ser resolvido por especialistas. Se assim é, o título deste artigo logo se esclarece, mostrando o que há de comum entre documentação e segurança nacional. Não nos antecipemos, porém. Antes de analisar a relação entre uma coisa e outra, procuremos precisar o conceito de documentação, ainda hoje muito discutido.

\section{2 - O MODERNO CONCEITO DE DOCUMENTAÇÃO}

Para isso teremos de caracterizar o fenômeno conhecido como explosão bibliográfica, pois foi ele que deu origem à documentação. A explosão bibliográfica tem sido comparada à explosão demográfica, sendo interessande recordar que foi um cientista social e não um documentalista ou um bibliógrafo quem primeiro aproximou demografia de bibliografia.

Em artigo públicado na importante revista francesa L'Année Sociologique, volume correspondente a 1952, Victor Zoltowski de. finiu bibliografia como uma "ciência concreta" cujo objetivo é recensear o mundo dos livros na sua totalidade, tal como a demo. grafia procede no recenseamento da população", O bibliógrafo acrescentou Zoltowski - não precisa de ler todos os livros para conhecer o universo bibliográfico, assim como um demógrafo que estuda os movimentos da população não necessita de conhecer pessoalmente cada cidadão. ${ }^{6}$

\section{1 - A explosão bibliográfica}

O fenômeno que se convencionou chamar de explosão bibliográfica é típico de uma época de acelerado e verdadeiramente explosivo desenvolvimento da ciência e da tecnologia. $\mathrm{O}$ aumento extraordinário da produção de livros e documentos é, ao mesmo tempo, causa e efeito desse desenvolvimento. É causa dele na medida em que as idéias novas, embora aparentemente acidentais, 
são o produto de informações acumuladas na memória consciente ou inconsciente do pequisador e do inventor. Referindo-se aos autores que o antecederam, dizia Isaac Newton: "se vi mais longe foi porque subi às costas de gigantes $" ;^{7}$ e Anísio Teixeira definia pesquisa como "utilização do conhecimento existente para a descoberta de novos conhecimentos". 8

O progresso da ciência e da tecnologia, por sua vez, projeta-se nos meios científicos e técnicos através de documentos. "Tudo no mundo existe para acabar em livro", disse Stéphane Mallarmé em lúcida observação ${ }^{9}$ que um cientista dos nossos dias confirmaria ao escrever: "a ciência é um muro de livros para o qual cada cientista contribui com uma pedra". ${ }^{10}$

\section{2 - A explosão científica e tecnológica}

A explosão bibliográfica, é, assim, uma decorrência natural da explosão científica e tecnológica, da qual daremos, a título de ilustração, apenas três exemplos. Entre as descobertas de Hans Christian Oersted, André Marie Ampère e Michael Faraday e as primeiras aplicações práticas da eletricidade, passaram-se mais de quarenta anos; vinte a vinte e cinco anos separaram depois os trabalhos de Heinrich Rudolf Hertz sobre a propagação das ondas elétricas e sua aplicação à telegrafia sem fio; entre a descoberta da fissão do urânio e a primeira reação nuclear em cadeia passaram-se apenas três anos, seguidos, outros três anos depois, pela explosão da bomba atômica sobre Hiroshima, em agosto de 1945.

A distinção entre pesquisa básica e aplicada tem sentido apenas didático, na medida em que as duas se tornaram interdependentes. Como observa Milton Burton, professor de Química na Universidade de Notre Dame, "se um astrofísico quiser aprender mais coisas sobre o espaço remoto terá de utilizar a maciça máquina ótica de um observatório; igualmente, "um telescópio de radar com setenta metros de comprimento, montado sobre trilhos € uma estrutura de vigas, controlado de forma a permanecer automaticamente focado num remoto objeto do espaço, constitui uma necessidade científica". Por sua vez, "as observações astrônômicas através da espectroscopia ótica exigem plataformas es. paciais a fim de que os dados recolhidos não venham a ser afetados pelos artefatos introduzidos pela nossa própria atmosfera". torna-se agora ciência".11

Os exemplos de explosão científica e tecnológica poderiam multiplicar-se facilmente porque a nossa época caracteriza-se pe- 
la aceleração em todos os setores da atividade humana. É uma época de velocidades e de explosões jamais imagináveis pelos nossos antepassados. A própria cultura - produto, no passado, de uma elite que trabalhava em silêncio e sem pressa - transformou-se em indústria e compete com os demais produtos da era tecnológica. Podemos ler, nas cidades em que moramos, as grandes revistas do mundo - Time, Newseek, The Economist, L'Express, Le Point, Der Spiegel, etc - na própria semana em que aparecem nos seus respectivos países. E já aconteceu que um romance do grande economista e homem de letras norte-americano John Kenneth Galbraith foi lançado ao mesmo tempo em inglês, em Nova York, e em português, no Rio de Janeiro, graças aos entendimentos entre o autor e seu amigo Carlos Lacerda, que traduziu e editou a obra. Este simples fato torna-se espetacular quando nos lembramos de que, para ser conhecido apenas no continente europeu, onde foi publicado em 1773, o romance Os Sofrimentos do jovem Werther, de Goethe, levou cinco anos; o Don Quixote, de Cervantes, publicado no início do século XVIII, levaria vinte anos; e também para ser conhecida em toda a Europa. a Divina Comédia gastou mais de quatro séculos. ${ }^{12}$

Segundo Derek de Solla Price - chefe do Departamento de História da Ciência na Universidade de Yale e autor de trabalhos notáveis em sua especialização - dobram em cada cem anos o número de verbetes de um dicionário biográfico nacional; em cada cinqüenta anos a força de trabalho, a população e o número de universidades; em cada vinte anos, o produto nacional bruto e as descobertas importantes; o número de grandes físicos e o de elementos químicos conhecidos, a exatidão dos instrumentos e o número de matrículas nos colleges norte-americanos; em cada quinze anos o número de bacharéis em artes e em ciências, o de revis. tas científicas, etc. O mesmo autor calcula em cerca de 50.000 o número de revistas científicas publicadas no mundo, desde as primeiras - a inglesa Philosophical Transactions e a francesa Journal des Sçavans - das quais 30.000 ainda estão em circulação. ${ }^{13}$

Note-se que não estamos nos referindo à produção de livros, que apesar de avassaladoramente crescente, não tem para o desenvolvimento da ciência e da tecnologia a mesma importância dos artigos de revistas e de outros documentos de circulação res. trita ao micro-meio científico, sem falar nos classificados como reservados ou secretos. Porque embora o objetivo bibliográfico se. ja derivado, etimologicamente, de palavra latina que significa livro, ao qualificar o substantivo explosão ele é usado numa acepção mais ampla, que inclui todos os documentos textuais, qualquer 
que seja sua forma de reprodução: datilográfica, mimeográfica, tipográfica, xerográfica etc. Assim, quando falamos em explosão bibliográfica estamos nos referindo aos seis milhões de documen. tos que são produzidos anualmente em todo o mundo, segundo o cálculo de Derek de Solla Price. ${ }^{14}$

\section{3 - DISPERSÃO DA INFORMAÇÃO DE INTERESSE PARA A SEGURANÇA NACIONAL}

Note-se também que dos seis milhões de documentos produzidos em cada ano foram excluídos os de caráter reservado ou secreto, embora não seja fácil distinguir informação científica de informação estratégica, com o advento da Guerra Total, conforme destaca Washington Platt na sua obra Strategic intelligence pro. duction, editada no Brasil com o título de A produção de informações estratégicas. ${ }^{15} \mathrm{De}$ qualquer modo, informa Philip Morrison que somente a Central Intelligence Agency - a já famosa CIA. dos Estados Unidos - possui trinta milhões de documentos mime. ografados. ${ }^{16}$ Como existem nos Estados Unidos não apenas um, mas vários serviços de inteligência - fenômeno que também ocorre em outros países - podemos concluir pela existência de uma explosão bibliográfica apenas nas áreas da segurança nacional e defesa externa.

De 1626 a 1961 publicaram-se no mundo 400 enciclopédias e dicionários especializados em assuntos militares, segundo bibliografia editada pela Rice University, de Houston, Texas. ${ }^{17} 483$ revistas especializadas na mesma área - semanais, quinzenais, mensais, bimestrais, trimestrais, quadrimestrais, semestrais circulam atualmente no mundo. ${ }^{18}$ sem contar as anuais e as de periodicidade irregular, que totalizam 71.19 A Air University, dos Estados Unidos, conseguiu localizar, em 30 bibliotecas daquele país e do Canadá, apenas 356 dessas publicações periódicas e se-
riadas. ${ }^{20}$

A perspectiva torna-se mais sombria quando pensamos no fenômeno da dispersão, que consiste na divulgação de artigos especializados em revistas gerais e de outras especializações. O documentalista inglês S. C. Bradford chegou a estabelecer, depois de cuidadosa pesquisa bibliográfica e cálculos estatísticos pertinentes, uma lei segundo a qual apenas um terço dos artigos especializados é publicado em revistas dessa especialização, dispersando os dois terços restantes em revistas de outras especializações conexas ou não - e nas de caráter geral. ${ }^{21}$ Para ilustrar essa lei com alguns exemplos recentes, recordaremos que em revista francesa de idéias - Les Temps Modernes - encontra- 
mos dois artigos de interesse militar, ${ }^{22}$ e que a também conceituada revista L'Année Sociologique divulga em seu último volume um artigo no qual são relacionadas a etnosociologia e a matemática. ${ }^{23}$

O fenômeno da dispersão é inevitável porque decorre da intenção cada vez maior entre todos os campos do saber: integração que destruir as velhas barreiras entre ciências exatas, ciências biológicas, ciências sociais e até entre estas e as chamadas Humanidades. Que relações poderiam supor os antigos que existisse entre religião e economia? Foi, entretanto, baseado em estudos de história das religiões e de economia que Max Weber demonstrou ligação entre o desenvolvimento do capitalismo e a ética protestante. ${ }^{24}$

\section{4-BIBLIOGRAFIA MILITAR NO BRASIL.}

Apesar do nosso País ser mais consumidor do que produtor de informação especializada, a documentação nacional de interesse militar não é nada desprezível, como podemos verificar examinando a Bibliografia Brasileira de Ciências Sociais, que a partir do volume 2, correspondente ao ano de 1955, referenciou livros e artigos de autores brasileiros sobre Forças Armadas, selecionados e classificados pelo então coronel Luiz Maia Filho. ${ }^{25}$ Apreciando três séculos de literatura militar brasileira, o general Francis. co de Paula Cidade salientou não ser fácil "traçar limites à literatura militar, não obstante sua definição que excluiu numerosas publicações, tais como leis, decretos, ordens de serviço etc. ${ }^{n 2}$ Além dos documentos legislativos e normativos a que se refere o general Paula Cidade, existem os documentos universitários ou acadêmicos, inteiramente desprezados, no Brasil, pelas bibliografias tradicionais, quando nos Estados Unidos são objeto de um só inventário sistemático : o realizado periodicamente pela University Microfilms, de Ann Arbor, com a publicação Dissertations Abs. tracts International, em cuja parte B (dedicada às ciências e à engenharia) são referenciadas muitas teses sobre assuntos aeroespaciais, engenharias aeronáutica e naval, ciências do mar etc. ${ }^{27}$

Diante dessa explosão de documentos de natureza variadíssima, que devem ser reunidos, selecionados, classificados, catalogados, referenciados, resumidos, indexados, traduzidos, e reproduzidos para utilização pelos interessados, não é mais possível escarnecer dos que estudam, enaltecendo apenas o saber de experiências feito a que se refere Camões. As escolas militares de pós-graduação - como, entre nós, as de Comando e Estado-Maior 
das Três Armas e a Escola Superior de Guerra - mostram que o ver, tratar e pelejar tão enfaticamente louvados pelo poeta, em detrimento do planejar e estudar, não bastam em nossos dias de Guerras Totais e de explosão documental.

\section{5 - BIBLIOTECONOMIA E DOCUMENTAÇÃO}

Caracterizado, embora em linhas gerais, o fenômeno da explosão bibliográfica, procuraremos demonstrar a importância da documentação em face desse fenômeno. Pode-se dizer sem exagero que a explosão bibliográfica apanhou de surpresa os bibliotecários de feitio tradicional. Voltados para o ideal da cultura popular e da educação de adultos, eles não se aperceberam de que um novo tipo de usuário começava a surgir, em conseqüência do desenvolvimento da ciência e da tecnologia : o especialista interessado menos em livros do que em artigos de revistas, em comunicações a congressos, em relatórios de pesquisas, em teses universitárias, em documentos de circulação restrita. É evidente que a esse tipo de usuário também não interessavam as velhas bibliografias e os tradicionais catálogos de bibliotecas, contendo apenas os dados externos dos documentos. O pesquisador precisa de saber em que medida os novos tipos de documentos contêm informações relevantes para suas investigações e isso a biblioteca e a bibliografia tradicionais não Ihe oferecia. Uma autora francesa afirmou que "a ciência encontrou seu Waterloo nas bibliotecas ${ }^{n} .28$

Para atendimento desse novo tipo de usuário é que surgiram os serviços de documentação e, com eles, os documentalistas, combatidos por certos bibliotecários aos quais faltou a iniciação filosófica necessária para compreender que as posições mais aparentemente antagônicas se conciliam em sínteses dialéticas e o conhecimento de história das idéias que os teria evitado repetir conflitos entre novas e velhas ciências, como ocorreu, por exemplo, com a História e a Sociologia. Os debates entre bibliotecários que defendiam e atacavam a documentação assumiu, por vezes, aspectos de história coletiva, contribuindo para muita confusão - ainda hoje persistente - entre biblioteconomia e documentação.

O conflito se assemelha à disputa, no campo das ciências sociais, entre a História e a Sociologia. Leia-se, a propósito, a contribuição de Fernand Braudel, intitulada "Histoire et Sociologie", na obra coletiva organizada por Georges Gurvitch. ${ }^{29}$ E do próprio Gurvitch, sua obra mais recente, Dialectique et sociologie. ${ }^{30} \mathrm{O}$ nos- 
so Gilberto Freyre, sempre tão sugestivamente imagista em sua expressão literária, compara o advento da Sociologia a "uma nova nação ou uma nova república fundada por separatistas" 31

Foi como surgiu a Documentação : como um movimento separatista dentro da Biblioteconomia. Em certo trecho do estudo supra indicado, referiu-se Fernand Braudel ao que os sociológogos procuram e os historiadores já vinham fazendo. Muitos bibliotecários disseram o mesmo dos documentalistas, acrescentando que a Documentação não passava de novo nome para exprimir o que eles tradicionalmente já faziam.

Não acreditamos que seja este um modo feliz e adequado de encarar o problema, mas uma simples escamoteação do mesmo. Das ciências do livro ou do texto - a Paleografia e a Diplomática, a Bibliologia e a Bibliografia, a Biblioteconomia e a Arquivística, a Documentação e a Ciência da Informação - podemos dizer o que Fernand Braudel escreveu das ciências sociais, isto é, que elas se impõem umas às outras, cada qual pretendendo captar o social - em nosso caso, a informação - na sua totalidade e cada uma se intrometendo no terreno de suas vizinhas, acreditando permanecer no próprio. ${ }^{32}$ Mas, como esclarece o mesmo autor, "todas as ciências do homem, incluindo a história, estão contaminadas uma pelas outras, falam ou podem falar o mesmo idioma". 33 Para concluir este paralelo, digamos da Biblioteconomia e da Documentação o que Georges Gurvitch disse da História e da Sociologia : "Estamos persuadidos de que o recurso infatigável à diversidade dos processos operatórios de dialetização é o único capaz de conduzir a uma colaboração confiante e frutuosa entre estas duas ciências". ${ }^{34}$

O fato é que as duas atividades têm objetivos distintos, embora de modo algum antagônicos. Compete à Biblioteconomia reunir, organizar e difundir documentos de qualquer natureza, principalmente livros, discos e filmes. O campo da Documentação é, ao mesmo tempo, mais restrito e mais amplo. Restrito quando ao tipo de documento, que é geralmente o textual, mas não inclui o livro a não ser excepcionalmente, limitando-se aos artigos de revistas, às comunicações a congressos, aos relatórios de pesquisas etc. . Amplo quanto ao processo, que consiste em resumir o conteúdo desses documentos e em deles extrair palavras-chaves para publicação periódica de resumos (abstracts) e índices temáticos; em utilizar processos mecânicos e automáticos na elaboração desses resumos e índices, nisto se associando à linguística, à logística simbólica e à ciência do processamento automático da informação, isto é, a informática. 


\section{6 - COORDENAÇÃO dOS ORGANISMOS DE DOCUMENTAÇÃO}

Do processo documentológico surge um produto : o documento secundário, qualificação que tem sentido técnico e não pejorativo: é o documento que só existe em função de outro por ele resumido ou codificado. Para tornar esse produto internacionalmente acessível, serviços de tradução e de reprodução foram desenvolvidos e coordenados em níveis nacional e internacional. Tenta-se presentemente criar um sistema internacional de informação científica e técnica, sob os auspícios da Unesco e do Conselho Internacional de Organizações Científicas. ${ }^{35}$ A participação nesse sistema exige de cada nação o estabelecimento de serviços de documentação devidamente coordenados.

Trata-se de estabelecer, no Brasil, um Sistema Nacional de Informação Científica e Tecnológica, cujo projeto, ainda em estudos, teve origem nas Metas e Bases para a Ação do Governo, de setembro de $1970{ }^{36} \mathrm{Em}$ trabalho recente, a diretoria da Biblioteca Nacional observou com razão que "o emprego corrente da palavra rede (network), na literatura especializada, parece refletir duas idéias : a de que nenhum sistema de informação é auto-suficiente e a de que existe acentuada tendência para organização de sistemas, ligados por redes de cooperação, preferentemente à adoção de grandes sistemas". 37

O panorama internacional, entretanto, não é dos mais animadores. Existem grandes sistemas nacionais, de caráter interdisciplinar, como, por exemplo, o francês - Centre National de la Recherche Scientifique - e o russo - VINITI, isto é, Vsessojuznyj Institut Naucnoj i Teckniceskoj Literatury (título transliterado do Instituto Federal para a Informação Científica e Técnica. E existem sistemas especializados de âmbito internacional - o caso do Chemical Abstracts Service e o do Biological Science Information Service - e nacional, como, por exemplo, o Defense Documentation Center, dos Estados Unidos, anteriormente denominado ASTIA, isto é, Armed Services Techinical Information Agency.

Para indexação - neologismo que, segundo alguns, deve ser substituído por indexificação e, segundo outros, por indicização dos documentos reunidos no Defense Documentation Center existe uma lista de palavras-chaves ou descritores - como são modernamente chamadas - de 8.000 termos : o Thesaurus of ASTIA descriptors. ${ }^{38}$ Recente enciclopédia sobre sistema se serviços de documentação existentes no mundo indica 23 de aeronáutica, 19 de tecnologia espacial, 11 de foguetes e mísseis, 7 de ciência militar

R. Serv. públ., Brasilla, 109 (1) Jan./mar. 1974 
em geral, 5 de defesa aérea, 5 de astronáutica, 4 de ciência naval e 1 para cada uma das seguintes subespecializações : guerra anfíbia suprimentos, engenharia naval, mobilização militar, páraquedismo e fotografia aérea. ${ }^{39}$

\section{7 - UM SERVIÇO DE DOCUMENTAÇÃO NO EMFA}

Acreditamos que competiria ao Estado-Maior das Forças Armadas, como órgão que tem, entre outras atribuições, a de "coordenar as informações no campo militar", ${ }^{40}$ articular-se com tais serviços de documentação, de alguns dos quais poderia até receber, além de informações, cooperação técnica para organização do seu próprio sistema documental. Somente dispomos, no Brasil, de levantamentos bibliográficos de natureza retrospectiva, como, além da já citada obra do general Francisco de Paula Cidade, os índices de revistas militares nacionais elaborados pelo tenente-coronel Francisco Ruas Santos ${ }^{41}$ e as Notas para uma bibliografia naval brasileira, de Guilherme de Andréa Frota. ${ }^{42}$

Não podemos conceber serviços de documentação no Exército, na Marinha e na Aeronáutica a não ser como extensões de um serviço central no EMFA e por este órgão coordenado. A montagem de tal serviço deve ser precedida naturalmente de um inquérito que defina os perfis de interesse dos usuários. "A difusão seletiva" - informa Jacques Chaumier - "é uma redistribuição parcial da informação, de acordo com o seu conteúdo, às pessoas ou grupos de pessoas afetadas segundo o interesse dispensado a certos tipos de informações. A difusão seletiva das informações é atualmente um modo de difusão em rápido desenvolvimento, porquanto proporciona uma informação personalizada aos utilizadores". 43

Outra medida preliminar - a ser tomada concomitantemente com a anteriormente indicada - é a elaboração de um thesaurus, instrumento indispensável para indexação dos documentos. O grande número desses documentos exige um serviço mecanizado ou mesmo automatizado. Mas, cuidado com os cantos-de-sereia dos vendedores de equipamentos mecânicos e eletrônicos! A aquisição ou aluguel de tais equipamentos deve ser atribuição exclusiva de quem vai trabalhar com eles, com a indispensável consultoria de especialistas em análise de sistemas e processamento de dados: nunca de fabricantes ou seus representantes e distribuidores. Esse, entretanto, foi o procedimento ado. tado por vários órgãos públicos do nosso País.

O fenômeno, aliás, não é apenas brasileiro, como revela um artigo publicado na Revue Internationale des Sciences Administra- 
tives, cujo autor - especialista das Nações Unidas - refere-se a aquisição de computadores como símbolo de prestígio, do que resultam "inúmeros casos de computadores sem utilização ou com subutilização, nos serviços públicos". O mesmo especialista aconselha o estabelecimento de uma política geral de utilização de computadores, informando o tradutor e comentador do artigo ser este o caso em nosso País, da criação da CAPRE (Comissão de Coordenação das Atividades de Processamento Eletrônico). ${ }^{44}$

Em seu importante estudo sobre Informática na administra. ção de pessoal, o professor João Luis Martins Ney da Silva escreve: "O inconveniente a ser evitado por uma nova política do Go. verno, nesse particular, é o da atual escolha preferencial de em. presas estrangeiras para prestação de serviços que empresas nacionais poderão executar com igual técnica, independentemente da marca dos equipamentos a serem utilizados, e com maior conhecimento, sem dúvida, dos nossos próprios problemas".

"Naturalmente" - continua o mesmo autor, hoje com a responsabilidade de uma das subchefias do Gabinete Civil da Presidencia da República - "a eliminação desse inconveniente é de interesse nacional, e requer uma legislação mais consentânea com esse interesse, na qual seja vedado que empresas fornecedo. ras de equipamentos para o sistema informático participem em empresas de prestação de serviços (como se faz nos Estados Unidos) ou com elas entrem em concorrência".45

Pelas suas próprias finalidades e atribuições, pela sua tão diversificada organização, pela natureza dos órgãos, sob sua jurisdição e daqueles junto aos quais mantém representantes, deve o EMFA constituir, quanto antes, um serviço de documentação, se nâo das proporções, da mesma natureza do Defense Documentation Center dos Estados Unidos. Numa época de explosão bibliográfica, somente um serviço de documentação possibilitará ao Estado-Maior das Forças Armadas o aprimoramento de seu pessoal, de acordo com o ideal previsto por Camões para o militar perfei-
to :

"Tal há de ser quem quer, com o dom de Marte, Imitar os llustres e igualá-los :

Voar com o pensamento a toda parte,

Adivinhar perigos e evitá-los

Com militar engenho e sutil arte,

Entender os inimigos, e enganá-los,

Crer tudo, enfim; que nunca louvarei

O Capitão que diga : Não Cuidei" ${ }^{46}$

R. Serv. públ., Brasília, 109 (1) Jan./mar. 1974 


\section{REFERENCIAS BIBLIOGRAFICAS}

1 - CAMOES, Luís de. Os Lusíadas, canto X, estrofe 153.

2 - SILVA, Maurício Rocha e. A evolução do pensamento científico. São Paulo, Editora de Humanismo, Ciência e Tecnologia, 1972, p. 290 e segs.

3 - WILSON, E. Bright, Jr. An introduction to scientific research. New York, McGraw-Hill, 1952, p. 10.

4 - SETON-WATSON, Hugh. Neither war nor peace; the struggle for po. wer in postwar world Rev. ed. New York, Praeger, 1962. 510 p. (Praeger paperbacks, PPS-97)

5 - FREYRE, Gilberto. "Em torno do avigoramento dos modernos executivos". Revista do Serviçc Público (Brasília) v. 108, n. ${ }^{\circ} 2$, p. 23-36 maio/agosto 1973 (trecho citado à p. 28)

6 - ZOLTOWSKI, Victor. "Les cycles de la création intellectuelle et artistique". L Année Sociologique (Paris) 3. Sér. (1952). Paris, Presses Universitaires de France, 1955, p. 163-206.

7 - NEWTON, Sir Isaac. Citado por Michael Crowe em "A ciência um século atrás", in : Crosson, Frederick J., ed. O impacto da ciência nas mudanças sociais. Trad. de Hélio Pólvora. Rio de Janeiro, Forum Editora, 1969, p. 111.

8 - TEIXEIRA, Anísio \& SILVA, Maurício Rocha e. Diálogo sobre a lógica do conhecimento. São Paulo, EDART, 1968, p. 30.

9 - MALLARME, Stéphane. "Le livre, instrument spirituel". In : Oeurvres complètes. Paris, Gallimard, 1945, p. 378.

10 - MOLES, Abraham A. "Cité scientifique et cité humaine". In : Poirier, René, ed. Entretiens en marge de la science nouvelle. Paris, Mouton, 1963 , p. 235.

11 - BURTON, Milton. "Introdução: análise retrospectiva". In : Crosson, Frederick J., ed. O impacto da ciência nas mudanças sociais, op. cit. Ver n. ${ }^{\circ}$ 7) p. 11.

12 - ESCARPIT, Robert. La révolution du livre. 2. éd. rev. et mise à jour, 1969. Paris, Unesco, 1972, p. 22.

13 - PRICE, Derek J. de Solla. Little science, big science. New York, Columbia University Press, 1965, p. 6-9 (A Columbia paperback, 62)

14 - PRICE, Derek J. de Solla. loc. cit.

15 - PLATT, Washington. A produção de informações estratégicas. Tradutores: Capitão Heitor Aquino Ferreira e Major Alvaro Galvão Pereira. Rio de Janeiro, Agir, 1967. p. 31-32. 
16 - MORRISON, Philip. "Ciência, educação e o futuro da humanidade". In : Crosson, Frederick J., ed. 0 impacto da ciência nas mudanças sociais, op cit. (ver n. 7) p. 204.

17 - CRAIG, Hardm. A bibliography of encyclopedias and dictionaries deaing with military, naval and maritime affairs, 1626-1959. Houston, Rice University, Fronden Library, 1960. 45 f. 2. ed. : 1577-1961, publicada em 1962. 70 p.

18 - ULRICH'S international periodicals directory. 14. ed. 1971-72. New York, R. R. Bowker, 1971. 2 v.

19 - IRREGULAR serials \& annuals; and international directory. 2. ed. New York, R. R. Bowker, 1972. 3.382 p.

20 - ESTADOS UNIDOS. Air University. Libraries. Union lis of foreign military periodicals Preliminary ed. Ed. by Paul $H$. Spence and Helen J. Hopewell. Alabama, Maxwell Air Force Base, 1957. 72 p.

21 - BRADFORD, S. C. Documentação. Trad. de M. E. de Mello e Cunha. Rio de Janeiro, Ed. Fundo de Cultura, 1961, p. 196-216.

22 - BRUNN, Julien. Travail scientifique et stratégie militaire". Les Temps Modernes (Paris) n. 320, p. 1.593, avril 1973.

PIGNON, Dominique Le scientifique et le militaire". Idem, p. 1.545.

23 - PICARD, Philippe-Charles. "Ethno-sociologie de la mathemátique". L'Anné Sociologique (Paris) v. 22, p. 13-47, 1971.

24 - WEBER, Max. The protestant ethik, and the spirit of capitalism. London, Allen \& Unwin, 1930. 292 p. Sobre o assunto, recomendamos o ensaio de José Honório Rodrigues, "Capitalismo e protestantismo", in : - Notícia de vária história. Rio de Janeiro, Livraria São José, 1951, p. 9-42.

25 - BIBLIOGRAFIA Brasileira de Ciências Sociais. v. 1 - . 1954 Rio de Janeiro, Instituto Brasileiro de Bibliografia e Documentação. 1955 - . Em 1955 foram referenciados 98 trabalhos; em 1956, 117; em 1957, 39; em 1958, 5; em 1959, 5; em 1960, 91; em 1961, 19; no volume correspondente aos anos 1962/64, 17.

26 - CIDADE, Francisco de Paula. Síntese de três séculos de literatura militar brasileira. Rio de Janeiro, Est. Gráf. Cordeiro de Farias, 1959. $607 \mathrm{p}$.

Ver, sobre legislação militar, o monumental Indice da Legislação do Exército. Rio de Janeiro, Estabelecimento General Gustavo Cordeiro de Farias, 1961 - . (Manual técnico T 27-290).

27 - DISSERTATIONS Abstracts International. B : The Sciences and Engieering. Ann Arbor, University Microfilms, $1938-$.

28 - BRIET, Suzanne. Qu'est-ce que la documentation? Paris, Editions Documentaires, Industrielles et Techniques, 1951. 48 p. (Collection de documentologie, 1)

R. Serv. públ., Brasília, 109 (1) Jan./mar. 1974 
29 - BRAUDEL, Fernand. "Histoire et sociologie". In: Gurvitch, Georges, ed. Traité de sociologie Paris, Presses Universitaires de France, $1958-60$, t. 1, p. 83-98.

30 - GURVITCH, Georges. Dialéctia e sociologia. Trad. de Manuel Vitorino Dias Duarte. Lisboa, Publicações Dom Quixote, 1971, p. 318.

31 - FREYRE, Gilberto. Sociologia; introdução ao estudo dos seus princípios. 5. ed. Rio de Janeiro, José Olympio em convênio com o Instituto Nacional do Livro, 1973, t. 1, p. 56.

32 - BRAUDEL, Fernand. loc. cit.

33 - Ibidem.

34 - GURVITCH, Georges, loc. cit.

35 - UNESCO. Unisist; informe del estudio sobre la posibilidad de establecer un sistema mundial de información científica. Montevideo, Oficina de Ciências de la Unesco para América Latina, 1971. 176 p. (SC. 70/D. 75/S)

36 - COSTA, João Frank da. "O Sistema Nacional de Informação Científica e Tecnológica (SNITS)". Revista da Biblioteconomia de Brasília v. 1, n. 2, p. 95-107, julho/dezembro 1973.

37 - MONTE-MOR, Jannice. A Biblioteca Nacional e o Sistema Nacional de Informação Científica e Tecnológica (SNITC). Trabalho apresentado ao $7 .^{\circ}$ Congresso Brasileiro de Biblioteconomia e Documentação, Belém, 1973. $21 \mathrm{f}$. mimeografadas.

38 - CHAUMIER, Jacques. As técnicas documentais. Trad. de Jorge de Sampaio. Lisboa, Publicações Europa-América, 1973, p. 70.

39 - KRUZAS, Anthony T. \& SCHNITZER, Anna Ercoli, ed. Encyclopedia of information systems and services. Orange, N. J., Academic Media, 1971. $1.109 \mathrm{p}$.

40 - SARDENBERG, Idálio. "O EMFA - sua missão e organização e o seu significado no contexto político-militar brasileiro". Revista Militar Brasileira (Rio de Janeiro) v. 98, p. 23-46, janeiro/junho 1972.

41 - SANTOS, Francisco Ruas. Coleção bibliográfica militar. Rio de Janeiro, Bibiloteca do Exército Editora, 1960, 783 p. Contém índice e notas bibliográficas de publicações periódicas - Revista do Exército Brasileiro (1882-1889), Revista Militar (1889-set. 1908), Boletim Mensal do Estado-Maior do Exército (1911-1923) e Nação Armada (1939-1947)

- e estudo crítico de obras sobre assuntos militares.

42 - FROTA, Guilherme de Andréa. Notas para uma bibliografia naval brasileira. Rio de Janeiro, Revista Marítima Brasileira, 1967. $36 \mathrm{p}$.

43 - CHAUMIER, Jacques. op. cit., p. 21.

44 - MUHAMMAD, Fagir. "O uso de concepções e técnicas administrativas modernas na administração pública". Trad. de Araújo Cavalcanti. Revista do Serviço Público (Brasília) v. 108, n. 2, p. 173-208, maio/ agosto 1973 (trecho citado à p. 195) . 
45 - NEY DA SILVA, João Luis Martins. Informática na administração de pessoal. Brasília, DASP. Centro de Documentação e Informática, 1971, p. 51-52.

46 - CAMŌES, Luís de. Os Lusíadas, canto VIII, estrofe 89.

\section{ABSTRACT}

\section{Documentation and national security}

The modern concept of national security - which encompass all the nation's resources and not only the military technology - has great implications for documentation.

The bibliographic explosion is a consequence from the great scientific and technological development as well as the close concetion between science and technology.

The library science and the emergence of documentary techniques of abstracting, indexing, and dissemination of information is compared with the conflict between history and sociology, as we can see, for example, in the writings of Fernand Braudel and Georges Gurvitch.

The scattering of information for national security among periodical publications of different specialization shows the need of and interdisciplinary documentation center for the armed forces.

In the Brazilian "Estado-Maior das Forças Armadas" a documenttation center must follow the example of the United States's Defense Documentation Center, coordinating services for the Army, the Navy, and the Air Force.

The use of electronic equipment must be preceded by an inquiriy among the potential users of this documentation center, which must provide personalized information. Automatic systems must not be planned by the computer's producers, as professor João Luis Ney da Silva has shows in his essay on the informatics in public administration.

NOTA

Neste artigo o autor expandiu a conferência que teve a honra de ler no Estado-Malor das Forcas Armadas, em 24 de outubro de 1973, por iniciativa do Vice-Almirante Herick Marques Caminha, Vice-Chefe do EMFA e sob a presidência do General-de-Exército Arthur Duarte Candal da 